\title{
Workplace Accommodations for Employees with Disabilities: A Multilevel Model of Employer Decision-Making ${ }^{1}$ \\ Apsara Telwatte, Jeromy Anglim ${ }^{2}$, Sarah K. A. Wynton, Richard Moulding
} Deakin University

Citation Information: Telwatte, A., Anglim, J., Wynton, S. K. A., \& Moulding, R. (2017). Workplace Accommodations for Employees with Disabilities: A Multilevel Model of Employer Decision-Making. Rehabilitation Psychology. Advanced Online Access. http://dx.doi.org/10.1037/rep0000120

Initial submission: August 2015; Accepted for publication: November 2016

\begin{abstract}
Purpose: Existing research suggests that the decision to grant or deny workplace accommodations for people with disabilities is influenced by a range of legal and non-legal factors. However, less is known about how these factors operate at the within-person level. Thus, we proposed and tested a multilevel model of the accommodation decision-making process, which we applied to better understand why people with psychological disabilities often experience greater challenges in obtaining accommodations. Method: A sample of 159 Australian adults, composed mostly of managers and HR professionals, read 12 vignettes involving requests for accommodations from existing employees. The requests differed in whether they were for psychological or physical disabilities. For each vignette, participants rated their empathy with the employee, the legitimacy of the employee's disability, the necessity for productivity, the perceived cost, and the reasonableness, and indicated whether they would grant the accommodation. Results: Multilevel modeling indicated that greater empathy, legitimacy, and necessity, and lower perceived cost predicted perceptions of greater reasonableness and greater granting. Accommodation requests from employees with psychological disabilities were seen as less reasonable and were less likely to be granted; much of this effect seemed to be driven by perceptions that such accommodations were less necessary for productivity. Ratings on accommodations were influenced both by general between-person tendencies and within-person appraisals of particular scenarios. Conclusions: The study points to a need for organizations to more clearly establish guidelines for how decision-makers should fairly evaluate accommodation requests for employees with psychological disabilities and disability more broadly.
\end{abstract}

\footnotetext{
${ }^{1}$ APA owns the copyright to this work. This article may not exactly replicate the authoritative document published in the APA journal. It is not the copy of record. The link provided by the above doi links to the copy of record.

2 Apsara Telwatte, Jeromy Anglim, Sarah K. A. Wynton, and Richard Moulding School of Psychology, Deakin University, Geelong, Australia. Correspondence concerning this article should be addressed to Jeromy Anglim, School of Psychology, Deakin University, Locked Bag 20000, Geelong, 3220 Australia. Email: jeromy.anglim@deakin.edu.au
} 
Keywords: accommodations, disability, psychological disability, discrimination, vignettes

\section{Impact}

(Point 1) Only limited research has examined employer decision-making behavior when evaluating workplace accommodations and less is known about the disability and accommodation characteristics that influence the employer decisionmaking process. This current study offers several advances over existing research including (a) a non-student sample of human resource professionals and managers, (b) responses in relation to a large number of accommodation scenarios, (c) measurement of employer characteristics, and (d) a multilevel modeling approach. This allowed for an overall examination of the importance of both between-person employer characteristics, as well as within-perceptions of various accommodation scenarios on the overall decision to grant accommodation requests. (Point 2) Results suggest that features of the person, the decision making process, and the context of the accommodation combine to influence perceptions of reasonableness and the willingness to grant an accommodation. In particular, contact with people with disability, knowledge of legislation, and positive attitudes to people with disabilities predicted a greater willingness to grant accommodations. Of particular importance, results showed that accommodation requests for psychological disabilities were perceived by employers as less legitimate, less necessary, and less reasonable, and were less likely to be granted. (Point 3) It may be beneficial for employers to adapt policy and training to further address the needs of employees with psychological disabilities. It may also be useful for employers to review and formalize what is a reasonable and necessary accommodation for employees with psychological disabilities.

\section{Introduction}

In order to reduce the personal and societal costs associated with the low workforce participation rates of people with disabilities, many countries have enacted legislation that requires employers to make reasonable changes to the workplace in order to better accommodate employees with disabilities (e.g., Americans with Disabilities Act of 1990; Americans with Disabilities Amendments Act of 2008; Australian Disability Discrimination Act of 1992; United Kingdom's Disability Discrimination Act 1995). While the precise wording differs between jurisdictions, the general requirements are that accommodation requests should be granted where an employee has a legally recognized disability, the accommodation allows the employee to do their job, and the cost of making the accommodation is not excessive. While these laws are designed to protect people with disabilities, their application can involve some subjectivity. From a legal perspective, a person tasked with making a decision about an accommodation request needs to consider whether the condition represents a legitimate disability, whether the requested modification would be effective, and whether the cost is reasonable. In addition to the purely legal question related to entitlements, a range of other factors may influence the decision-maker, such as the employer's empathy towards the employee, their attitudes towards people with disabilities, their experience, and their knowledge of disability legislation. Understanding this decision making process is important for organizations seeking to a positive corporate culture around disability, people with disabilities seeking to 
attain accommodations, and rehabilitation psychologists seeking to assist clients in the workplace (Bricout \& Bentley, 2000).

Several studies have examined the accommodation request process (e.g., Allen \& Carlson, 2003; Carpenter \& Paetzold, 2013; Dong, Oire, MacDonaldWilson, \& Fabian, 2013; Markel \& Barclay, 2009), finding that a wide range of employee, accommodation, and employer characteristics influence the decision of whether to grant an accommodation. In particular, studies suggest that people with psychological disabilities may experience additional challenges in obtaining workplace accommodations (Colella, Paetzold, \& Belliveau, 2004; Gouvier, SytsmaJordan, \& Mayville, 2003). Given the challenges of conducting field research on actual accommodation decisions, some studies have used a vignette-based approach (e.g., Carpenter \& Paetzold, 2013; Florey \& Harrison, 2000; Gouvier et al., 2003). Despite the insights gained from existing studies, there is a need to refine models of the accommodation decision-making process. Specifically, existing vignette studies have tended to use only a small number of vignettes per participant (e.g., Carpenter \& Paetzold, 2013; Koser, Matsuyama, \& Kopelman, 1999), which has limited the ability to distinguish within- and between-person effects on the decision to grant accommodation requests. Furthermore, reliance on traditional statistical approaches such as analysis of variance has limited the capacity to examine within-person effects of factors like perceived cost and necessity on the decision to grant (e.g., Florey \& Harrison, 2000; Gouvier et al., 2003). Finally, some existing studies have relied on student samples rather than using managers and HR professionals who are required to make accommodation requests as part of their job (e.g., Gouvier et al., 2003; Hazer \& Bedell, 2000).

In light of this gap in the literature, the primary aim of the current study was to refine understanding of the process by which employers make decisions about accommodation requests. We also aimed to apply this model to examine the relative willingness of decision-makers to grant accommodations to employees with physical as opposed to psychological disabilities. Finally, we examined the relationship between employer characteristics and accommodation decision-making. To achieve these aims, the present study involved a sample of Australian managers and HR professionals appraising and making decisions about whether to grant accommodation requests from existing employees in twelve scenarios. The primary vignette manipulation was whether the disability was physical or psychological; vignettes also varied with respect to the severity of the disability and the cost of the accommodation being requested. Participants rated each vignette in terms of empathy experienced towards the employee, the legitimacy of the disability, the necessity of the accommodation for productivity, the cost of the accommodation, the reasonableness of the accommodation request, and whether the request should be granted. We used multilevel modeling to estimate the within-person effects of vignette characteristics and vignette appraisals on the decision to grant. To further explore individual differences we correlated the between-person factors of knowledge of disability legislation, attitudes towards disability, and experience with appraisal, with average granting tendencies on the vignettes. 


\section{Conceptual Framework}

The present study draws on several frameworks for conceptualizing the accommodation request process. In broad terms, Stone and Colella's (1996) multidimensional framework highlights how treatment of people with disabilities occurs within a legal, cultural, and organizational context. In relation to the accommodation decision-making process, we draw on Florey and Harrison (2000) who categorized factors influencing this process into characteristics of (a) the employee, (b) the accommodation request, and (c) the employer receiving the request. They further conceptualized the sequence of psychological reactions involved in the decision-making process in a model that was broadly influenced by the theory of planned behavior (Fishbein \& Ajzen, 1975)-focusing on performance instrumentality, perceptions of fairness, and on attitudes, obligation, and intentions. We were particularly interested in understanding how employers apply legal and nonlegal principles to a particular accommodation scenario. Thus, in the present study we focused on how employers assessed the legal rights of an employee, and the degree to which emotional reactions influence perceptions of reasonableness and the decision to grant an accommodation. A conceptual overview and outline of this decision process is presented in Figure 1.

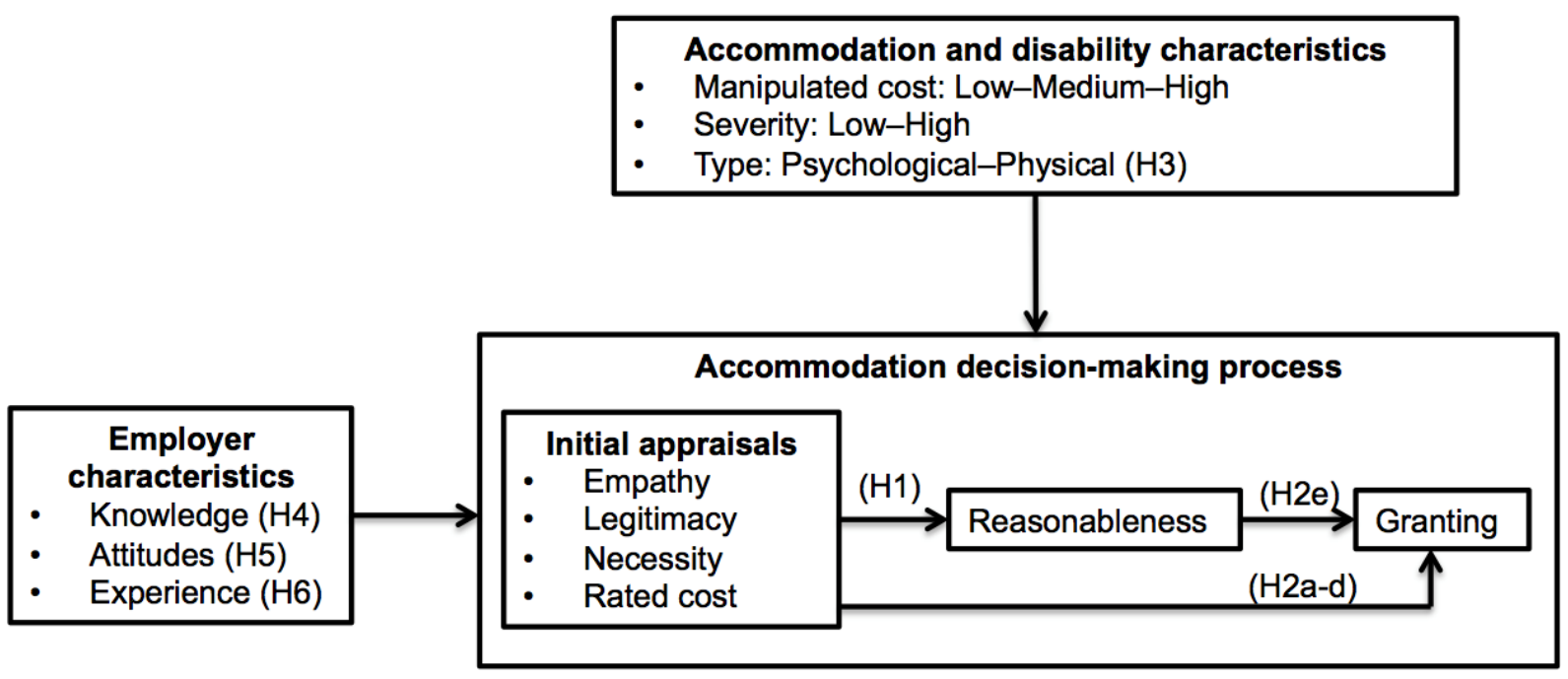

Figure 1. The diagram represents a summary of variables related to accommodation decision-making examined in the current study. Employer characteristics represent between-person effects and accommodation characteristics and appraisals represent within-person effects. Hypotheses of effects of disability and employer characteristics focus on their effect on average perceptions of reasonableness and granting. Manipulated cost of making the accommodation and the severity of the disability are included to expand generality of the model and are discussed further in the method.

\subsection{Accommodation Decision Process}

The decision to grant an accommodation can be seen from a range of perspectives including legal, economic, emotional, and political viewpoints (Stone \& Colella, 1996). Decision makers may be influenced by a range of non-legal factors 
such as their empathy for the employee, political factors and the broader organizational consequences of making a given decision (Colella, 2001; Florey \& Harrison, 2000). From a legal perspective decision-makers generally need to determine whether the employee has a legitimate disability and whether the accommodation request is reasonable by balancing the predicted cost of implementing a requested accommodation with the predicted benefit to the employee's productivity. In most cases the cost of accommodations is small. While the exact cost of workplace accommodation is not well documented in many countries, surveys of employers in the United States have indicated that 59\% of workplace accommodations cost nothing while those that did have a cost, included an average one-time expenditure of US\$500 (Loy, 2016). In practice, an accommodation is commonly considered reasonable if the employee qualifies for such an accommodation and the accommodation requested does not pose undue hardship on an organization (Carpenter \& Paetzold, 2013; Florey \& Harrison, 2000). Even when viewing the decision through a legal lens, employers are still required to exercise judgment to determine whether the person has a disability and how costs, benefits, and overall reasonableness should be appraised.

Whether for legal or economic reasons, research has shown that employers typically perform a cost-benefits analysis when deciding whether to grant accommodations (e.g., Baldridge \& Veiga, 2001; Lee, 1997; Schartz, Hendricks, \& Blanck, 2006). Jackson, Furnham, and Willen (2000) found that employers were more likely to provide cheaper and less disruptive accommodations. Similarly, Carpenter and Paetzold (2013) found that employers were more likely to grant requests when they perceived the accommodation to be useful. Furthermore, research supports the idea that when individuals empathize with people with disabilities, they are more likely to engage in helping behavior (Colella, 2001). In particular, Carpenter and Paetzold (2013) found that empathy towards employees seeking workplace accommodations significantly influenced granting behavior. Thus, we expected decision-makers to assess reasonableness of an accommodation based partially on formal factors of the legitimacy of the disability, the necessity for productivity, and the perceived cost, and partially on interpersonal factors related to empathy and a desire to help the employee. Thus,

Hypothesis 1: Judgments of (a) greater empathy, (b) greater legitimacy, (c) greater necessity, and (d) lower cost will be associated with judgments of greater reasonableness.

Hypothesis 2: Judgments of (a) greater empathy, (b) greater legitimacy, (c) greater necessity, (d) lower cost, and (e) greater reasonableness will be associated with greater levels of granting of accommodation requests.

Furthermore, while we expected that empathy would positively correlate with reasonableness and granting, we wanted to examine whether empathy incrementally predicts reasonableness and granting over-and-above cost, necessity, and legitimacy judgments. If empathy is an important predictor, then it may be that influencing the attitudes of decision-makers may be as important as having clear policy. Finally, we also wanted to examine the extent to which reasonableness judgments explain the effect of cost, legitimacy, empathy, and necessity on granting, and the relative importance of these factors. 


\subsection{Employee, Disability, and Accommodation Characteristics}

Studies have identified a range of employee and accommodation characteristics that influence the outcome of the accommodation request. Two important features of the accommodation request are the cost of the accommodation and the degree to which it is effective in improving performance (Florey \& Harrison, 2000). Research also suggests that employees' comfort with requesting accommodations from their employer is an important factor in influencing whether a request is made in the first place (e.g., Baldridge \& Veiga, 2001; Bruyere, Erickson, \& VanLooy, 2004 2004; Schur et al., 2014 Kruse, Bruyère, \& Blanck, 2014). Researchers have also examined a range of employee features including disability type, disability severity (Carpenter \& Paetzold, 2013), and whether the disability is perceived to be self-inflicted (Miller \& Werner, 2005). For example, Carpenter and Paetzold (2013) used vignette-based study where presented disabilities varied in severity and found that employers perceiving a disability as self-inflicted were less likely to grant an accommodation than those who perceived the disability to be genetic or without self-cause.

Psychological versus physical disabilities. Of relevance to the present study, several studies suggest that employees with psychological disabilities experience greater difficulty obtaining both employment in general, and workplace accommodations in particular (Colella et al., 2004; Gouvier et al., 2003; Miller \& Werner, 2005). A psychological disability can be defined as an impairment concerned with consciousness, perception, mood, volition, emotions, or behavior, which has lasted for a period of more than six months and that results in a loss or abnormality of function (Australian Bureau of Statistics, 1998). In Australia, individuals with psychological disabilities have some of the lowest employment participation rates. For example, in 2009, the employment rate of Australians aged 15-64 years was $49.7 \%$ for people with physical disabilities compared with $29.2 \%$ for people with psychological disabilities (Australian Bureau of Statistics, 2012). Popovich, Scherbaum, Scherbaum, and Polinko (2003) found that surveyed employers reported physical disabilities to be more legitimate than psychological disabilities. Similarly, Koser et al. (1999) asked HR professionals to make a hypothetical hiring decision that involved selecting between an applicant who was a wheelchair user and one that was taking medication for depression. They found that HR professionals were seven times more likely to select the employee with the physical disability as opposed to the psychological disability. Compounding this issue, research suggests that employees with psychological disabilities are often reluctant to seek workplace accommodations (e.g., Brohan, Henderson, Little, \& Thornicroft, 2010; Dalgin \& Bellini, 2008; Irvine, 2011; Jans, Kaye, \& Jones, 2012).

There are many reasons why employers may be less likely to grant an accommodation request from employees with psychological disabilities. First, the lower perceived legitimacy of psychological disabilities (Popovich et al., 2003) may be due to lay beliefs about psychological disorders. Second, physical disabilities often have more obvious, external markers of disability status. Third, decision-makers may have different normative beliefs about the appropriateness of accommodations needed for psychological disabilities. Finally, decision-makers may have different beliefs about the necessity of accommodations in relation to psychological 
disabilities; this includes both whether an accommodation is sufficient to restore productivity and whether it goes beyond what is required (Florey \& Harrison, 2000) . Thus, we expected psychological disabilities to be perceived as less legitimate, less necessary for productivity, and less reasonable. We also expected decision-makers to experience somewhat less empathy. Thus,

Hypothesis 3: Accommodation requests based on psychological disabilities will be rated lower on (a) empathy, (b) legitimacy, (c) necessity, and (d) reasonableness, and (e) will be less frequently granted than those based on physical disabilities.

\subsection{Contextual and Organizational Factors}

While beyond the scope of the present study, we note the importance of both characteristics of the organization and the broader social, cultural, and legal context. Many studies support the idea that a organizational culture is important for how employers treat employees with disabilities (Butterworth, Whitney-Thomas, \& Shaw, 1997; Ellison, Russinova, MacDonald-Wilson, \& Lyass, 2003; Gates, 2000; Schur, Kruse, \& Blanck, 2005). For example, Gilbride, Stensrud, Vandergoot, and Golden (2003) identified various organizational characteristics related to better treatment of employees with a disability including flexible management style, employers focused on worker performance rather than disability, and senior management expecting and rewarding diversity. Similarly, Florey and Harrison (2000) found that robust accommodation policies strengthened compliance and adherence to policy amongst employers, and that strong policy sought to reduce the effect of negative employer attitudes.

\subsection{Characteristics of the Accommodation Decision-Maker}

Researchers have examined the effect of a range of employer characteristics on the accommodation process including knowledge, attitudes, and experience with disabilities (e.g., Banks, Novak, Mank, \& Grossi, 2006; Corrigan et al., 2008; Diksa \& Rogers, 1996; Hand \& Tryssenaar, 2006).

Knowledge of disability legislation. In order for disability legislation to influence practice, employers need to know the law. Several findings suggest that greater knowledge of disability legislation influences accommodation granting behavior (e.g., Brohan et al., 2010). Jackson et al. (2000) found that adequate knowledge of relevant disability legislation was correlated with employer compliance with disability legislation and accommodation behavior. In general, knowledge of legislation should lead to decisions that are more consistent with the law. Scheid (1999) reported that providing information on legislation led to greater granting of accommodation requests. Given that the law in many Western countries is generally supportive of accommodations, we might expect the following.

Hypothesis 4: Greater knowledge of legislation will be associated with (a) greater perceptions of reasonableness and (b) greater levels of granting of accommodation requests.

Attitudes to people with disabilities. In general, attitudes towards people with disabilities are multifaceted (Gething \& Wheeler, 1992). In particular, several aspects are relevant in the employment context, including beliefs about the productivity of employees with disabilities, willingness to help employees with disabilities, and general distress levels when being in the presence of employees with 
disabilities. A common finding is that more positive employer attitudes towards people with disabilities is associated with greater granting of accommodations. In a vignette study, Florey and Harrison (2000) found that managers who had a more positive attitude towards accommodation requests were more likely to grant accommodations. Jackson et al. (2000) found that positive attitudes by personnel directors and managers towards people with disabilities was correlated with compliance with disability legislation. Thus,

Hypothesis 5: More positive attitudes to people with disabilities will be associated with (a) greater perceptions of reasonableness and (b) greater levels of granting of accommodation requests.

Experience. Greater contact and experience of employers in working with people with a range of disabilities may also be related to a greater willingness to accommodate (Gilbride et al., 2003; Hand \& Tryssenaar, 2006). While raising questions of the causal direction of the association, in a survey of employers Scheid (1999) found that a history of employing people with psychological disabilities was a significant predictor of their willingness to comply with disability legislation. Brohan et al. (2010) surveyed British employers and found that greater social contact was associated with a greater willingness to hire people with psychological disabilities. Greater social contact may help to reduce negative stereotypes of people with disabilities and may increase the desire to help people with disabilities. Furthermore, experience making accommodation requests may increase the decision-maker's understanding of the legal requirements, as well as create a cycle of feedback where the decision-maker can learn about the effectiveness of accommodations in improving employee productivity. Thus, overall, we expected more positive attitudes to people with disabilities and more experience with people with disabilities to be positively correlated with greater empathy for people with disabilities and higher levels of granting and perceived reasonableness of accommodation requests. Thus,

Hypothesis 6: More experience with people with disabilities will be associated with (a) greater perceptions of reasonableness and (b) greater levels of granting of accommodation requests.

\section{Method}

\subsection{The Australian Context}

The current study was conducted in Australia. In general, the regulatory context in Australia is similar to other developed countries that have implemented laws around reasonable accommodations for people with a disability as set out in the United Nations Convention on the Rights of Persons with Disabilities. In Australia, accommodation requests for people with disabilities are regulated federally by the Disability Discrimination Act (DDA) of 1992. In addition, each state has its own antidiscrimination legislation which largely replicates the federal law and serves to cover gaps in jurisdiction. Australian law provides an inclusive definition of disability that covers a broad range of psychological, physical, and others disabilities. In most cases, Australian law requires employers to make what are called "reasonable adjustments" to the workplace. The requirement for employers to make reasonable adjustments is implied by laws that prohibit indirect discriminate against employees with a disability. An adjustment is defined as reasonable "unless making the adjustment 
would impose an unjustifiable hardship" on the employer (DDA, 1992). Thus, while reasonableness involves balancing the need for the change with the cost of making the change, it imposes a strong requirement to make adjustments. In addition to undue hardship, there are several narrow exceptions, where employers could refuse to make an accommodation, including (a) if after making the change, the employee would still not be able to perform the genuine requirements of the job, (b) the employer has been granted an exemption under an official standard, or (c) if making the adjustment would threaten the health and safety of any person.

The federal government and each state of Australia has a human rights commission. One role of these commissions is to promote the rights of people with a disability and provide information to employers about their responsibilities under the law. They also provide an alternative dispute-resolution process that is designed to resolve issues more informally to reduce the need for court action. In addition, most larger organizations should have training and documentation related to compliance with equal opportunity and anti-discrimination legislation. In some cases, this will include specific training on making workplace adjustments. It may also discuss practical examples of what changes are considered reasonable (e.g., provision of appropriate equipment, flexible work arrangements, training, etc.) and what is not considered reasonable (e.g., changing inherent requirements of the job, creation of a different job, maintaining a job that is redundant, and promotion). Furthermore, workplace accommodations are not just a legal issue, rather employers may voluntarily make changes because they see the benefits for productivity and employee well-being.

Despite this positive and proactive regulatory environment, it is less clear how this has translated into organizational action. While it is difficult to compare statistics across countries due to varying definitions of disability, as with the United States and the United Kingdom, people with a disability are less likely to be employed, more likely to be unemployed, and more likely to be under-employed. In general these differences are greater for people with psychological disabilities. For example, the unemployment rate (which excludes people not looking for work) in Australia was $18.9 \%$ for psychological disability, $7.5 \%$ for physical disability and $5.1 \%$ for no known disability (Australian Bureau of Statistics, 2012). In 2010, the United States census reported that less than one-half of individuals aged 21 to 64 with a disability were employed $(41.1 \%)$ compared with $79.1 \%$ of people without disabilities. In the United Kingdom 2008 employment rate for non-disabled people was $79.5 \%$. This was compared to various disabilities with lower employment rates including problems with back or neck (43.1\%) and difficulty in seeing (47.2\%) along with mental illness, phobia and panics (13.0\%) (Riddell, Edward, Weedon, \& Ahlgren, 2010).

\subsection{Participants}

To increase the validity of our findings, we actively sought to recruit participants whose job may involve making decisions about workplace accommodations. We contacted organizations who had members, clients, or employees who had such jobs. Participating organizations then sent emails to potential participants inviting them to participate in the study. Participants were informed that the purpose of the study was to examine the decision-making processes 
related to workplace accommodations for employees with disabilities. After answering the demographic questions, participants then completed 12 vignettes presented in randomized-order, to control for carry-over effects. Finally, participants completed several scales measuring knowledge of disability legislation and attitudes to people with disabilities. The study received ethics approval from the Deakin University, Faculty of Health, Human Ethics Advisory Group.

The sample consisted of 159 Australian adults (65.4\% female) with ages ranging from 23 to 67 years $(\mathrm{M}=43.7, \mathrm{SD}=9.9)$. The majority of participants were managers and in a HR role $(57 \%), 17.6 \%$ were managers not in a HR role, $18.2 \%$ were in a HR role but were not managers, and $6.9 \%$ were neither managers nor in a HR role. Most were employed in large organizations (500+ employees 64.2\%; 51-500 employees $20.1 \%)$. The majority $(85.4 \%)$ also reported having at least some experience with evaluating accommodation requests. Participants came from a wide range of industries with the most prevalent being education (17.9\%), government administration and defense $(15.9 \%)$, health and community services $(7.9 \%)$, property and business services (5.3\%) and manufacturing (4.6\%), and retail $(2.6 \%)$. Participants were generally working full-time $(78.0 \%)$, part-time $(12.6 \%)$ or were self-employed (12.6\%). Participants were mostly drawn from the states of Victoria $(66.0 \%)$ ad New South Wales (16.7\%). Most participants had a postgraduate qualification $(65.2 \%)$ or a university degree $(26.6 \%)$, and all participants had completed secondary schooling.

\subsection{Vignettes}

Twelve vignettes were developed for this study. Each vignette required the participant to evaluate and make a decision about a hypothetical employee with a legally recognized disability who was requesting a workplace accommodation. The primary manipulation of interest was type of disability (physical or psychological). However, vignettes were also varied in severity of disability (low or high), and manipulated cost of implementing the accommodation (low, moderate, or high). All three factors were fully crossed (i.e., $2 \times 2 \times 3$ design). The severity and cost manipulations were included to capture a greater breadth of scenarios. In general, more severe disabilities may make accommodations more necessary, and more expensive manipulations may be seen as less reasonable or necessary. Development of vignettes was informed by information and case studies made available on the website for the Job Accommodation Network (https://askjan.org). The final vignettes were refined following qualitative feedback and quantitative responses from an initial pilot sample $(n=8)$ from Australia, which included a range of content experts (e.g., psychologists, industrial / organizational psychology academics, nurses) and business professionals (e.g., consultants, business analysts). The disabilities used included mild bipolar symptoms (low severity psychological), a mild visual impairment (low severity physical), medically treated schizophrenia (high severity psychological), and a wheel-chair user with spinal chord injury (high severity physical). Descriptions of disabilities also gave an indication of symptoms experienced as they related to the job (e.g., "mild insomnia, occasional fatigue, and reduced energy"). Employee positions included executive assistants, administrative assistants, project managers, and consultants. A range of accommodation requests were used, including modified equipment, departmental training, provision of a private office, flexible work 
scheduling, and home-based work. Full vignette descriptions are available in the Online Appendix. An example vignette (low severity; low cost; physical) is:

You have an executive assistant, whose responsibilities include scheduling of meetings and appointments, preparing reports and presentations and overseeing office operations. He/she has recently been diagnosed with a mild visual impairment, which will impact all aspects of their role. He/she has requested a larger desktop monitor in their office.

For each vignette, participants responded to six items: (a) empathy: "This employee is someone with whom I can empathize"); (b) legitimacy: "Irrespective of the accommodation, I believe this specific disability to be a legitimate disability"; (c) necessity: "This specific accommodation is necessary for organizational productivity"; (d) rated cost: "What cost would you associate with this specific work accommodation?"; (e) reasonableness: "This work accommodation request is reasonable"; and (f) granting: "Would you grant this specific work accommodation request?". Response scales were $1=$ strongly disagree to $5=$ strongly agree for empathy, legitimacy, necessity, and reasonableness items, $1=$ very inexpensive to $5=$ very expensive for the cost item, and $0=$ no, $1=$ yes for the granting item.

\subsection{Measures}

Knowledge of Disability Legislation Survey - Australian Adaptation (KDLA). The KDLA was adapted from Hazer and Bedell (2000). The original scale measured knowledge of United States disability legislation. We adapted the items to reflect Australian disability legislation (see Online Appendix for item content). This involved removing four items that were deemed to be too easy or unclear and adding four items relevant to Australian HR practices including speaking with others about a disability to make employment decisions, and collecting information pertaining to the job. The scale consisted of 14 items. Each item was composed of a statement regarding rights and responsibilities of employers in relation to people with a disability. Participants indicated for each statement whether they believed it was a true or a false statement of the law. Knowledge of disability legislation was scored as the proportion of items answered correctly.

The overall alpha in our sample of the adaptation was a little lower than previous research; i.e., $\alpha=.41$ compared to Hazer and Bedell's (2000) $\alpha=.61$. However, this appeared to be due to the present sample being actual managers and HR professionals who were mostly very capable of answering the items correctly. The correct answer was the most frequently endorsed response for all items. The sample were correct over $95 \%$ of the time for 8 of the 14 items, and correct over $90 \%$ of the time for 11 of the 14 items. There were no negative corrected item-total correlations. Thus, the measure mostly highlights that in general the sample was very knowledgeable about disability legislation.

Attitudes to People with Disabilities. We measured three different attitude variables: productivity perceptions, helpfulness, and discomfort. The measures of productivity perceptions of disabled workers and helpfulness towards disabled workers (Scherbaum, Scherbaum, \& Popovich, 2005) included 7 items each. The productivity perceptions scale measures the degree to which a person believes that employees with disabilities tend to make a positive contribution to the workplace (e.g., the reversed item "Employees with disabilities slow down the rate at which 
work is completed"). The helpfulness scale is designed to measure a person's general willingness to positively interact with employees with a disability (e.g., "I would assist a new co-worker who was disabled in learning his or her new job"). Response options ranged from $1=$ extremely unlikely to $6=$ extremely likely. Scale scores were the mean after item reversal (see Online Appendix for full item descriptions).

The measure of discomfort was drawn from the Interaction with Disabled Persons Scale (IDPS; Gething \& Wheeler, 1992). The IDPS scale was originally a 21-item scale developed to measure the multifaceted attitudes that individuals have towards people with disabilities. Following extensive re-analyses, Iacono, Tracy, Keating, and Brown (2009) suggested that the main psychometrically defensible scale in the IDP was the discomfort scale. Thus, we report the scale that measures discomfort in interacting with people with a disability (items 9, 11, 12, 17, and 18). Items are answered on a scale of $1=$ disagree very much to $6=$ agree very much.

To examine the appropriateness of using these three scales as distinct measures of attitudes, a maximum likelihood factor analysis was performed on the productivity perceptions, helpfulness, and discomfort items in the present sample. The scree plot showed clear support for a three-factor solution (eigenvalues of first six components were $6.04,2.35,1.65,1.06,0.93,0.91$ ). Factor loadings following a promax rotation indicated a clean factor structure. All but two items loaded highly on their theorized factors, and there was only one cross-loading above .25 . These two items (item 1 and 3 of the productivity perceptions questionnaire) were both positively worded in a scale that was generally written negatively. Given their conceptual relevance and a desire to have a mix of positively and negatively worded items, these two items were retained. Of the items loading most on their primary factor, all but one had an absolute loading greater than .50. Cronbach's alphas were all at acceptable levels: productivity perceptions $(\alpha=.77)$, helpfulness $(\alpha=.80)$, discomfort $(\alpha=.83)$.

Experience with accommodations. Experience with accommodation requests was measured using a single item that was rated $0=$ no experience, $1=$ limited experience, $2=$ moderately experienced, 3 = highly experienced.

Psychological Disability Contact. The measure of contact with people with a psychological disability was a three-item composite. The first two items measured how much contact a person had with people with a psychological disability at work and outside of work respectively, scored $0=$ none to $3=$ regularly. The third item asked about the closest contact the person has with a person with a psychological disability, with scale points $0=$ no relationship, $1=$ customer, $2=$ co-worker, $3=$ friend, $4=$ family member, $5=$ partner, $6=$ yourself. The three items were summed to form an overall score and then divided by the maximum possible score of 12 . Thus, a value of zero indicates no contact and a value of one indicates the highest level of contact.

\subsection{Data Analytic Approach}

We used the lme4 package in R (Bates, Maechler, Bolker, \& Walker, 2014) to fit mixed effects models of the effect of vignette manipulations and ratings on vignette outcomes, focusing particularly on reasonableness ratings and granting. All models included a random intercept and all predictors were modeled with fixed effects. Predictors included employer characteristics which were z-score 
standardized. Within-person predictors included vignette factors and vignette ratings. Vignette factors were coded as follows: type of disability (physical $=-0.5$, psychological $=0.5)$, severity $($ low $=-0.5$, high $=0.5)$, and cost $($ low $=-0.5$, moderate $=0.0$, high $=0.5)$. Thus, the intercept represents the average rating over all vignettes, and the factor coefficients represent the expected change in rating when going from either physical to psychological, or from low to high.

Reflecting the theorized influence of decision variables, empathy, legitimacy, necessity, and cost ratings were modeled as a function of the three manipulated factors, whereas reasonableness and granting were modeled with both manipulated factors and decision variables as predictors. When decision variables were included as predictors, they were person-mean centered. For dependent variables other than granting, the models were linear mixed-models. However, because granting was a binary variable it was modeled using a generalized linear mixed model with a logit link. Thus, coefficients predicting granting can be interpreted in a similar way to how logistic regression coefficients are interpreted. To derive the probability of granting from the model coefficients it is necessary to apply the formula $\exp (x) /(1+\exp (x))$, where $x$ is the predicted value on the logistic scale obtained by adding an intercept value to the sum of coefficients multiplied by predictor values. To distinguish between effects of manipulated factors and ratings on reasonableness and granting, models with different predictor sets were compared. When predicting reasonableness, we estimated models separately based on whether predictors included manipulated factors or ratings. When predicting granting, we further estimated separate models with and without reasonableness as a predictor. This was done to assess the degree to which reasonableness explained the effect of other decision variables on the decision to grant an accommodation request.

\section{Results}

\subsection{Attitudes, Knowledge, Experience and Vignette Response Tendencies}

Table 1 presents descriptive statistics for employer characteristics and crosscorrelations with average vignette ratings. Overall, participants had moderate levels of contact with individuals with a psychological disability, some previous experience with accommodation requests, and high levels of knowledge of disability legislation (mean of 91\% of items correct). Participants generally had positive perceptions of the productivity of employees with disabilities, were willing to help employees with disabilities, and reported experiencing low levels of discomfort around individuals with a disability. The three attitudinal scales of productivity, helpfulness, and discomfort showed moderate intercorrelations; knowledge also positively correlated with productivity perceptions and helpfulness. The experience measures were associated with lower levels of discomfort (see Table A1 in online Appendix for correlations between these scales). 


\section{Table 1}

\section{Correlations of Employer Characteristics with Mean Values for Accommodation Decision-Making Process Variables in Vignettes}

\begin{tabular}{|c|c|c|c|c|c|c|c|c|c|c|}
\hline \multirow[b]{2}{*}{ Employer Characteristic } & \multicolumn{4}{|c|}{ Descriptive Statistics } & \multicolumn{6}{|c|}{ Correlations } \\
\hline & M & SD & $\begin{array}{c}\text { Skewnes } \\
\mathrm{s}\end{array}$ & $\begin{array}{c}\text { Kurtosi } \\
\text { S }\end{array}$ & $\begin{array}{c}\text { Empath } \\
\mathrm{y}\end{array}$ & $\begin{array}{c}\text { Legitimac } \\
\mathrm{y}\end{array}$ & $\begin{array}{c}\text { Necessit } \\
y\end{array}$ & $\begin{array}{c}\text { Rated } \\
\text { Cost }\end{array}$ & $\begin{array}{c}\text { Reasonablene } \\
\text { ss }\end{array}$ & $\begin{array}{c}\text { Grantin } \\
\mathrm{g}\end{array}$ \\
\hline Female $(0,1)$ & 0.65 & 0.48 & & & .14 & .21 & .10 & .11 & .07 & .08 \\
\hline Age (years) & 43.72 & 9.92 & 0.05 & -0.74 & .02 & -.03 & -.06 & .12 & -.02 & -.11 \\
\hline Psych disability contact $(0-1)$ & 0.47 & 0.23 & -0.23 & -0.45 & .17 & .19 & .19 & -.11 & .24 & .21 \\
\hline Experience with accommodation $(0-3)$ & 1.55 & 0.95 & -0.07 & -0.92 & .10 & .04 & .11 & -.02 & .07 & .00 \\
\hline Knowledge of legislation $(0-1)$ & 0.91 & 0.09 & -1.53 & 2.76 & .06 & .11 & .10 & -.23 & .16 & .23 \\
\hline Attitude: productivity perceptions $(1-6)$ & 4.65 & 0.74 & -0.15 & -0.63 & .23 & .34 & .32 & -.31 & .40 & .30 \\
\hline Attitude: Helpfulness (1-6) & 5.32 & 0.58 & -0.91 & 0.75 & .27 & .33 & .27 & -.24 & .29 & .23 \\
\hline Attitude: Discomfort (1-6) & 1.98 & 0.79 & 0.63 & -0.28 & -.04 & -.10 & -.09 & .09 & -.12 & -.04 \\
\hline
\end{tabular}

Note. $\mathrm{n}=159$. Female is coded $0=$ male, $1=$ female. Vignette variables (e.g., empathy, legitimacy, etc.) are the mean value over the 12 vignettes. Absolute correlations greater than or equal to .15 are significant $(p<.05)$ and are bolded. Scale range is shown in parentheses.

Cross-correlations shown in Table 1 test the hypothesized relationships between employer characteristics and mean vignette ratings. Supporting hypothesis 4, knowledge of legislation had a significant $(\mathrm{p}<.05)$ positive correlation with ratings of reasonableness $(r=.16)$ and grating $(r=.23)$. In relation to attitudes, more positive productivity perceptions and greater helpfulness were significantly associated with higher ratings of reasonableness ( $r=.40$ for productivity; $r=.29$ for helpfulness) and granting ( $r=.30$ for productivity; $r=.23$ for helpfulness), but distress was not significantly associated with vignette outcomes. Thus, Hypothesis 5 was only partially supported. The correlations for productivity perceptions and helpfulness tended to be larger than those for knowledge. Partially supporting Hypothesis 6, amount of psychological contact was significantly correlated with reasonableness $(r=$ $.24)$ and granting $(r=.21)$, while experience with making accommodation requests was not. We also examined the relationship of industry type (after combining related industries with small numbers of participants) and organizational size with vignette responses and found no significant relationships.

\subsection{Vignette Accommodation Decision Process}

The following section reports results from models of the relationships between manipulated factors and vignette responses. We present (a) descriptive statistics and intercorrelations of vignette ratings (see Table 2), (b) models of empathy, legitimacy, necessity, and rated cost, (c) models of reasonableness (see Table 3), and (d) models of granting (see Table 4).

Descriptive statistics and intercorrelations. Table 2 shows the intraclass correlations (ICCs), descriptive statistics and correlations at the between and withinperson levels for the vignette variables. The larger ICCs indicate that there was greater between-person variance in empathy $(60 \%)$ and legitimacy $(60 \%)$ than there 
was for the other vignette variables (ranging from $9 \%$ to $29 \%$ ), indicating they were influenced more by individual differences than by the vignette manipulations. The pattern of grand means [see $\mathrm{M}(\mathrm{M})$ in Table 2] indicated that participants generally empathized with the people in the vignettes $(\mathrm{M}=4.2$ on 1 to 5 scale) and saw the disabilities as legitimate $(\mathrm{M}=4.4$ on a 1 to 5 scale). On average, $80 \%$ of accommodations requests were granted.

While almost all intercorrelations of vignette ratings were statistically significant - supporting Hypothesis 1 that appraisals would predict reasonableness and Hypothesis 2 that appraisals and reasonableness would predict granting-several major patterns can be observed. First, the pattern of between-person correlations broadly mirrors that of the within-person correlations, except that the within-person correlations were somewhat smaller (the mean absolute correlation was .32 for within-person correlations compared to .46 for between-person correlations). This reduction appeared to be amplified for variables with larger ICCs (i.e., empathy and legitimacy). Second, as expected, if rated cost was reversed, then vignette ratings exhibited a generally positive pattern of correlations. Third, rated cost seemed to have weaker negative correlations with empathy $(\mathrm{r}=-.12$ between-person) and legitimacy $(\mathrm{r}=-.16)$ than it did with reasonableness $(\mathrm{r}=-.33)$ and granting $(\mathrm{r}=-.35)$. At the within-person level, reasonableness was very strongly related to granting $(r=.77)$, and necessity was the strongest other correlate of both reasonableness $(r=.71)$ and granting $(r=.63)$.

Table 2

Intraclass Correlations, Descriptive Statistics, and Correlations at BetweenPerson (Upper-Diagonal) and Within-Person (Lower-Diagonal) Levels for Vignette Variables

\begin{tabular}{lccccccccccc}
\hline Variable & $\mathrm{ICC}$ & \multicolumn{1}{c}{$\mathrm{M}(\mathrm{M})$} & $\mathrm{SD}(\mathrm{M}) \mathrm{M}(\mathrm{SD}) \mathrm{SD}(\mathrm{SD})$ & 1 & 2 & 3 & 4 & 5 & 6 \\
\hline 1. Empathy $(1-5)$ & .63 & 4.16 & 0.54 & 0.31 & 0.27 & & $\mathbf{. 6 9}$ & $\mathbf{. 5 1}$ & -.12 & $\mathbf{. 5 2}$ & $\mathbf{. 2 9}$ \\
2. Legitimacy $(1-5)$ & .60 & 4.39 & 0.46 & 0.27 & 0.25 & $\mathbf{. 3 8}$ & & $\mathbf{. 5 7}$ & $\mathbf{- . 1 6}$ & $\mathbf{. 5 7}$ & $\mathbf{. 3 3}$ \\
3. Necessity $(1-5)$ & .29 & 3.81 & 0.54 & 0.70 & 0.30 & $\mathbf{. 2 7}$ & $\mathbf{. 2 8}$ & & $\mathbf{- . 2 5}$ & $\mathbf{. 8 2}$ & $\mathbf{. 6 0}$ \\
4. Rated Cost $(1-5)$ & .23 & 3.07 & 0.64 & 0.98 & 0.32 & $\mathbf{- . 0 5}$ & .02 & $\mathbf{- . 1 5}$ & & $\mathbf{- . 3 3}$ & $\mathbf{- . 3 5}$ \\
5. Reasonableness $(1-5)$ & .20 & 3.81 & 0.48 & 0.78 & 0.30 & $\mathbf{. 3 0}$ & $\mathbf{. 2 7}$ & $\mathbf{. 7 1}$ & $\mathbf{- . 2 5}$ & & $\mathbf{. 7 9}$ \\
6. Granting $(0-1)$ & .09 & 0.80 & 0.16 & 0.33 & 0.19 & $\mathbf{. 2 3}$ & $\mathbf{. 2 3}$ & $\mathbf{. 6 3}$ & $\mathbf{- . 2 3}$ & $\mathbf{. 7 7}$ & \\
\hline
\end{tabular}

Note. Between-person correlations (upper-diagonal) are based on person-level means $(n=159)$. Within-person correlations (lower-diagonal and in italics) are based on person-mean centered observations $(n=1,908)$. Significant correlations are bolded $(p$ $<.05)$. ICC is the intra-class correlation using ICC(1) formula. M(M) is the mean of person-level means (i.e., the grand mean); $\mathrm{SD}(\mathrm{M})$ is the standard deviation of personlevel means; $\mathrm{M}(\mathrm{SD})$ is the mean of within-person standard deviations; $\mathrm{SD}(\mathrm{SD})$ is the standard deviation of within-person standard deviations. Scale ranges are shown in parentheses.

Models of empathy, legitimacy, necessity and cost. Multilevel models with manipulated cost, severity, and psychological disability as fixed effect predictors 
were run predicting empathy, legitimacy, necessity, and rated cost (see Table A2 in online Appendix for full results). The cost manipulation was effective with high cost vignettes rated 1.2 points higher than low cost vignettes on the 1 to 5 cost scale. As suggested earlier, empathy and legitimacy were less affected by the manipulations than were necessity and rated cost. Overall, participants indicated that they empathized slightly less with people in the psychological vignettes $(\beta=-0.15, p<$ $.001)$ and saw them as slightly less legitimate $(\beta=-0.13, p<.001)$. More prominently, psychological vignettes were rated as much less necessary $(\beta=-0.43, p$ $<.001)$, even though they were rated as less costly $(\beta=-0.35, p<.001)$. Taken together, these results support Hypothesis 3 that psychological disabilities would be appraised less positively in terms of empathy, and legitimacy.

Models of reasonableness. Table 3 shows the results for multilevel models predicting reasonableness from manipulated factors and vignette ratings. Model 1 shows in particular that more expensive accommodation requests were rated as much less reasonable $(\beta=-0.57, p<.001)$ as were those involving psychological disabilities $(\beta=-0.48, \mathrm{p}<.001)$. Severity was a significant predictor but had a far smaller effect $(\beta=-0.10, p<.01)$. Model 2 shows that while all four ratings predicted reasonableness, necessity was the main predictor $(\beta=0.72, p<.001)$. Finally, Model 3 predicts reasonableness from both manipulated factors and vignette ratings. While the coefficients for ratings showed minimal change for Model 3 compared to Model 2 , the effect of manipulated cost and disability type was substantially reduced in comparison to Model 1. The effect of manipulated cost went from -0.57 to -0.20 , and the effect of psychological disability went from -0.48 to -0.18 . Thus, the ratings, particularly necessity, partially explained the effect of vignette manipulations on reasonableness. These results support Hypothesis 1 that appraisals would predict reasonableness and Hypothesis 3 that accommodation requests relating to psychological disabilities would be perceived as less reasonable. Contact with people with physical disability and attitudes that people with disability are productive predicted greater mean reasonableness. 
Table 3

Multilevel Models Predicting Reasonableness Ratings from Manipulated Factors and Vignette Ratings

\begin{tabular}{lccc}
\hline & Model 1 & Model 2 & Model 3 \\
\hline Intercept & $3.81^{*}(0.04)$ & $3.81^{*}(0.03)$ & $3.81^{*}(0.03)$ \\
Employer Characteristics & & & \\
$\quad$ Female & $0.01(0.04)$ & $0.01(0.04)$ & $0.01(0.04)$ \\
Age & $0.01(0.04)$ & $0.01(0.04)$ & $0.01(0.04)$ \\
Psych disability contact & $0.10^{*}(0.04)$ & $0.10^{*}(0.04)$ & $0.10^{*}(0.04)$ \\
Experience with accommodation & $-0.01(0.04)$ & $-0.01(0.04)$ & $-0.01(0.04)$ \\
Knowledge of legislation & $0.02(0.04)$ & $0.02(0.04)$ & $0.02(0.04)$ \\
Attitude: productivity perceptions & $0.15^{*}(0.04)$ & $0.15^{*}(0.04)$ & $0.15^{*}(0.04)$ \\
Attitude: Helpfulness & $0.06(0.04)$ & $0.06(0.04)$ & $0.06(0.04)$ \\
Attitude: Discomfort & $0.05(0.04)$ & $0.05(0.04)$ & $0.05(0.04)$ \\
Vignette Factors & & & \\
Manipulated Cost & $-0.57^{*}(0.04)$ & & $-0.20^{*}(0.04)$ \\
Severity & $-0.10^{*}(0.03)$ & & $-0.07^{*}(0.03)$ \\
Type: Psychological & $-0.48^{*}(0.03)$ & & $-0.18^{*}(0.03)$ \\
Vignette Ratings & & & \\
Empathy & & $0.18^{*}(0.04)$ & $0.16^{*}(0.04)$ \\
Legitimacy & & $0.13^{*}(0.04)$ & $0.13^{*}(0.04)$ \\
Necessity & & $0.72^{*}(0.02)$ & $0.67^{*}(0.02)$ \\
Rated cost & & $-0.12^{*}(0.01)$ & $-0.10^{*}(0.02)$ \\
& & & \\
SD Intercept & & 0.41 & 0.41 \\
SD Residual & & 0.57 & 0.55 \\
Deviance & 0.38 & 3605.7 & 3538.2 \\
\hline Note. Numbers & 0.76 &
\end{tabular}

Note. Numbers represent estimates of fixed effects with standard errors in parentheses. Reasonableness is on a 1 to 5 scale. All employer characteristics were zscore standardized.

${ }^{*} p<.05$

Models of granting. Table 4 shows the results of the generalized multilevel models predicting granting. Specifically, generalized models with a logistic link function were used because the outcome measure (i.e., granting of accommodations) was a binary variable. Models 1, 2, and 3 largely mirror the results above predicting reasonableness. Model 1 indicates that lower cost accommodations $(\beta=-1.94, p<$ $.001)$ and, as expected, those involving physical disabilities $(\beta=-1.37, p<.001)$ were more likely to be granted. Model 2 shows that necessity was the strongest vignetterating predictor $(\beta=2.76, p<.001)$, followed by legitimacy $(\beta=1.14, p<.001)$. Model 3 combines ratings and manipulations factors. In this model the coefficients for vignette factors are somewhat reduced after the inclusion of the vignette ratings (e.g., manipulated cost went from -1.94 to -1.23 and psychological disability went 
from -1.37 to -0.88 ). The exact scale of this reduction is arguably greater than that implied by the raw changes in coefficients, because coefficients are on the logistic scale and the mean and standard deviation of the intercept get larger as additional explanatory variables are added to the model.

Model 4 shows that reasonableness is the strongest predictor of granting $(\beta=$ $4.29, \mathrm{p}<.001)$ and that this reduces the effect of the other four vignette ratings to the point where empathy is no longer statistically significant. Furthermore, Model 5 shows that manipulated factors are no longer statistically significant after adding reasonableness to the model. The negligible reduction in deviance from model 5 $($ deviance $=595.6)$ to model 4 (deviance $=600.7)$ also reinforces this point. These results support Hypotheses 2 that appraisals and reasonableness predict granting and Hypothesis 3 that accommodation requests relating to psychological disabilities are less likely to be granted than those relating to physical disabilities. The main significant employer characteristics that predicted higher levels of granting were contact with people with disabilities and perceptions that workers with disabilities are productive. 


\section{Table 4}

Generalized Multilevel Models with Logit Link Predicting Granting from Manipulated Factors and Vignette Ratings

\begin{tabular}{|c|c|c|c|c|c|}
\hline & Model 1 & Model 2 & Model 3 & Model 4 & Model 5 \\
\hline Intercept & $1.93 *(0.11)$ & $2.79 *(0.19)$ & $3.01 *(0.21)$ & $4.60 *(0.41)$ & $4.67 *(0.42)$ \\
\hline \multicolumn{6}{|l|}{ Employer Characteristics } \\
\hline Female & $0.02(0.10)$ & $0.02(0.16)$ & $0.02(0.17)$ & $0.10(0.26)$ & $0.10(0.26)$ \\
\hline Age & $-0.09(0.11)$ & $-0.13(0.16)$ & $-0.14(0.17)$ & $-0.33(0.26)$ & $-0.34(0.27)$ \\
\hline Psych disability contact & $0.26^{*}(0.11)$ & $0.38 *(0.17)$ & $0.42 *(0.18)$ & $0.53 *(0.27)$ & $0.53 *(0.28)$ \\
\hline Experience with accommodation & $-0.05(0.11)$ & $-0.15(0.17)$ & $-0.15(0.17)$ & $-0.03(0.27)$ & $-0.03(0.27)$ \\
\hline Knowledge of legislation & $0.16(0.10)$ & $0.21(0.16)$ & $0.24(0.17)$ & $0.31(0.26)$ & $0.34(0.26)$ \\
\hline Attitude: productivity perceptions & $0.33^{*}(0.12)$ & $0.43 *(0.19)$ & $0.43^{*}(0.20)$ & $0.84 *(0.31)$ & $0.85^{*}(0.32)$ \\
\hline Attitude: Helpfulness & $0.09(0.12)$ & $0.27(0.18)$ & $0.29(0.19)$ & $0.66^{*}(0.31)$ & $0.67^{*}(0.31)$ \\
\hline Attitude: Discomfort & $0.16(0.12)$ & $0.26(0.17)$ & $0.27(0.18)$ & $0.63 *(0.29)$ & $0.63^{*}(0.29)$ \\
\hline \multicolumn{6}{|l|}{ Vignette Factors } \\
\hline Manipulated cost & $-1.94 *(0.18)$ & & $-1.23^{*}(0.26)$ & & $-0.75^{*}(0.39)$ \\
\hline Severity & $-0.37 *(0.13)$ & & $-0.57^{*}(0.19)$ & & $-0.21(0.29)$ \\
\hline Type: Psychological & $-1.37 *(0.14)$ & & $-0.88 *(0.21)$ & & $-0.26(0.31)$ \\
\hline \multicolumn{6}{|l|}{ Vignette Ratings } \\
\hline Empathy & & $0.61 *(0.25)$ & $0.53 *(0.26)$ & $0.25(0.36)$ & $0.27(0.37)$ \\
\hline Legitimacy & & $1.14 *(0.28)$ & $1.17 *(0.29)$ & $0.82 *(0.40)$ & $0.82 *(0.40)$ \\
\hline Necessity & & $2.76 *(0.17)$ & $2.62 *(0.17)$ & $1.40 *(0.24)$ & $1.38 *(0.24)$ \\
\hline Rated cost & & $-0.77 *(0.10)$ & $-0.67 *(0.12)$ & $-0.52 *(0.15)$ & $-0.43 *(0.18)$ \\
\hline Reasonableness & & & & $4.29 *(0.37)$ & $4.23^{*}(0.38)$ \\
\hline SD Intercept & 0.89 & 1.45 & 1.55 & 2.45 & 2.49 \\
\hline Deviance & $1,585.0$ & $1,038.2$ & 989.0 & 600.7 & 595.6 \\
\hline
\end{tabular}

Note. Numbers represent estimates of fixed effects with standard errors in parentheses. All employer characteristics were z-score standardized. ${ }^{*} p<.05$

\section{Discussion}

Building on earlier work (e.g., Florey \& Harrison, 2000; Stone \& Colella, 1996) the current study aimed to refine models of the accommodation decisionmaking process, examine willingness to grant accommodations for psychological disabilities, and understand how employer characteristics influence the accommodation decision process. The study used multilevel modeling to examine the decision-making process of employers (i.e., managers and HR professionals) in response to accommodation vignettes. The results supported our predictions, indicating that reasonableness partially explained the effect of empathy, legitimacy, necessity, and cost ratings on granting behavior. Also, as predicted, participants were less likely to grant accommodations for employees with psychological disabilities as 
opposed to those with physical disabilities; they also perceived accommodations for employees with psychological disabilities as less reasonable. Finally, contact with a psychological disability, knowledge of legislation and work related attitudes, but not distress, were positively related to perceptions of reasonableness and granting.

\subsection{Accommodation Decision-Making Process}

The results were broadly in support of the proposed model of accommodation decision-making and add additional within-person support for related models (e.g., Carpenter \& Paetzold, 2013). Specifically, empathy, legitimacy, necessity, and rated cost all predicted reasonableness ratings, and reasonableness ratings partially explained the effect of these variables on willingness to grant accommodations. Thus, participants appeared to be combining legal reasoning related to perceptions of the legitimacy of the disability and cost-benefit analyses of the accommodation with emotional reasoning related to personal empathy when forming their judgments about what was a reasonable accommodation. However, given that all included disabilities were legitimate and legally protected, if a strictly legal approach were adopted, we would not expect an association between legitimacy and granting.

Beyond bivariate relationships, the size of the coefficients showed that necessity was a much stronger predictor of reasonableness and granting than was empathy, legitimacy, or rated cost. Thus, participants appeared to be giving particular weight to whether the proposed accommodation would actually allow the employee to perform his or her job effectively. Due to the nature of the vignettes, participants may have felt that some accommodations were excessive or went beyond what was required to merely accommodate the employee. For example, some participants may have felt that a job did not allow for working from home or that department-wide sensitivity training was excessive. Likewise, participants may have felt that the disability was too extreme for the accommodation to be effective in restoring acceptable standards of workplace functioning. While the present research gave employers a binary decision of whether or not to grant an accommodation, accommodation decisions in the field often involve a process of negotiation and discussion. Future research should explore how accommodations are negotiated and modified following initial employee requests.

\subsection{Psychological versus Physical Disabilities}

Results also indicated that the type of disability was related to willingness to grant an accommodation request. Specifically, accommodations related to psychological disabilities were granted much less commonly than were those for physical disabilities. Examination of other vignette ratings indicated that psychological disabilities were rated only slightly lower on scales of empathy and legitimacy, and were actually perceived to be less expensive. Based on the ratings, the main explanation for this lower level of granting was that participants perceived the accommodations for people with psychological disabilities to be substantially less necessary and less reasonable. These lower necessity ratings may have been driven by beliefs that accommodations related to physical disabilities would be more effective than those related to psychological disabilities in enabling employees to effectively perform their role. For example, psychological disabilities such as bipolar disorder might be perceived to have a greater negative effect on job performance than physical disabilities like a visual impairment. Alternatively, it may be that 
accommodations related to physical disabilities form a greater part of standard organizational practice, and that participants drew on such general concepts when judging what was reasonable.

While some differences in the response to psychological and physical disabilities may be appropriate, there was some indication of a bias against employees with psychological disabilities. For instance, participants perceived employees in the psychological conditions as having disabilities that were slightly less legitimate, despite such disabilities being equally legitimate from a legal perspective. In addition, the lower ratings of reasonableness and lower levels of granting for psychological disabilities was observed in five of the six combinations of manipulated cost and severity. This suggests that the differences were not due to any one set of accommodation or disability manipulations. Whilst limited research has explicitly investigated employer-granting behavior as a function of type of disability, these results support findings from Koser et al. (1999) and Corrigan et al. (2008) suggesting that employees with psychological disabilities are disadvantaged more than those with physical disabilities. Additional research is needed to investigate the reasons for any such bias and the generality of the bias to other jobs, specific disabilities, and types of accommodation.

\subsection{Employer Characteristics}

Finally, the results provide an understanding of the relationships between demographics, knowledge, attitudes, experience, and accommodation decisionmaking in a sample of managers and HR professionals. Encouragingly, participants generally understood disability legislation (mean of $91 \%$ correct), believed disabled employees could be productive (mean of 4.6 on a 1 to 5 scale), were keen to help (mean of 5.3 on a 1 to 6 scale), and reported experiencing low levels of discomfort in being around people with disabilities (mean of 2.0 on a 1 to 5 scale). Consistent with earlier work (e.g., Florey \& Harrison, 2000; Gilbride et al., 2003; Hand \& Tryssenaar, 2006) results also indicated that positive attitudes tended to intercorrelate and that knowledge of disability legislation was correlated with a willingness to help and with beliefs that employees with a disability could be productive. Finally, greater contact, knowledge of disability legislation, and positive attitudes (but not discomfort) were associated with both seeing accommodations requests as more reasonable, and with a greater willingness to grant accommodations.

\subsection{Implications}

This study's findings have implications for both employers and people concerned with improving the lives of people with disabilities. On the one hand, the results suggest that employers generally report positive attitudes to people with disabilities, and are generally acting appropriately, reinforcing the success of the broader context of laws, advocacy work, and organizational policy. Participants generally granted accommodation requests and generally put substantial weight on factors like necessity and cost in forming an assessment of reasonableness, in order to further guide decisions of whether or not to grant an accommodation. However, there were also signs that more work is needed to further legitimize psychological disabilities and their related workplace accommodations. Although correlational in nature, the findings point to legislative knowledge, attitudes, and experience being important mechanisms by which employers can influence workplace accommodation 
behavior. In particular, it may be beneficial for employers to adapt policy and training to further address the needs of employees with psychological disabilities. It may also be useful for employers to review and formalize what is a reasonable and necessary accommodation for employees with psychological disabilities.

There are also a range of other ways that managers and HR professionals can promote positive change in their organization. They can promote national mental health awareness initiatives in the workplace and speak positively about getting their workplace involved. They can also promote the importance of progressive and supportive disability policy in the organization. Managers also help to influence the corporate culture of their subordinates. By being approachable and showing a willingness to be flexible, employees may be more willing to approach them with disability requests.

While the current study examined the decision making process with respect to manager's granting disability requests, it also has practical application for rehabilitation psychologists and other professionals involved with clients with disabilities. In particular, while some characteristics of the accommodation process are dependent on individual difference characteristics of the manager and their history (e.g., previous experience of the manager with those with disability, empathy), other aspects of the process may be amenable to change. While clients should be made aware that while it is their legal right for reasonable accommodation requests to be granted, the likelihood of being granted depends on the nature of what managers see as being "reasonable" and necessary. Clients may need to be coached to give greater explanation to their managers regarding the need for adjustment for mental illness when compared with clients with physical illnesses, given the lower likelihood of their being granted; conversely this may help clients understand why their request has not been as fully accommodated as they would wish. As managers seem to particularly be weighing how the accommodation relates to the ability to do their job, this implies that helping clients couch their requests in such terms would assist in the success of the requests. Finally, clients should be aware of how cost impacts on the likelihood of granting. Of course, future studies should directly examine whether such factors can be manipulated in order to improve the chances of successful accommodations requests.

\subsection{Strengths, Limitations, and Future Research}

This study contains several limitations that should be noted. First, the study used intended accommodation behavior rather than actual behavior. Real world decisions are likely to be influenced by a range of additional factors including organizational policies, pre-existing relationships, specific job functions and industry standards, and a range of political factors. Although the study was anonymous, participants may also display social desirability biases when responding. Second, this study only looked at a subset of possible disabilities, employee characteristics, and accommodation requests. Third, while pilot testing aimed to make the psychological and physical disabilities and corresponding accommodations comparable, it may be that participants perceived these as different for idiosyncratic reasons. While this does not particularly affect the overall model of decision-making, it will be useful for future research to explore the generality of the present findings about psychological and physical disabilities. Fourth, the observed relationships between decision 
variables were based on observational data. Thus, alternative causal pathways and excluded variables may provide alternative explanations to the model in the present study. Fifth, given the nature of the study, participants with positive attitudes towards employees with disabilities may have been more willing to complete the study. Sixth, for each vignette, one-item scales were used to measure each construct of interest. While common in vignette designs, this generally results in lower reliability which in turn would attenuate observed effects. Seventh, similarly, the low internal consistency reliability obtained for the knowledge measure and the high level of kurtosis may attenuate observed correlations between knowledge and accommodation behavior. In future, it may be beneficial to user more items and a more challenging measure of disability legislation. Finally, this study sampled managers and HR professionals from Australia. While Australia has a similar legal context to other developed countries such as the United States and the United Kingdom, it will be useful for future researchers to examine how present findings generalize to other countries and legal contexts.

There are many avenues for future research, including the following. First, the vignette design could be extended to multiple countries to examine the influence of different social and regulatory contexts. Second, future research could further explore the beliefs that people hold about psychological disabilities and how they relate to workplace behavior. Third, further research is needed on the effectiveness of various organizational interventions including formal and informal education, participation in mental health events, management communication, and policy change. Finally, a longitudinal field-based study of how employers process actual accommodation requests would be particularly beneficial.

Overall, the present study provides several important insights into how employers think about people with disabilities and how they conceptually process accommodation requests. In particular, the combination of multilevel modeling, multiple vignettes, and multiple ratings per vignette helped to distinguish the withinperson effects of ratings on the decision to grant accommodations. For example, this helped to highlight the greater importance of necessity in accommodation decisions, which would have been lost using traditional data analytic approaches. This approach also helped to explain why a lower level of granting was observed for people with psychological disabilities. We hope that this study encourages others to further apply this methodological approach to explore the wide range of factors that influence the accommodation decision-making process and contribute to the broad aim of creating a more equitable and inclusive workplace for employees with disabilities. 


\section{References}

Allen, S., \& Carlson, G. (2003). To conceal or disclose a disabling condition? A dilemma of employment transition. Journal of Vocational Rehabilitation, 19(1), 19-30.

Australian Bureau of Statistics. (1998). Disability and Disabling Conditions, 1998. Retrieved from Canberra: Australian Bureau of Statistics. (2012). Australian Social Trends. Retrieved from Canberra:

Baldridge, D. C., \& Veiga, J. F. (2001). Toward a greater understanding of the willingness to request an accommodation: Can requesters' beliefs disable the Americans with Disabilities Act? Academy of Management Review, 26(1), 85-99.

Banks, B. R., Novak, J., Mank, D. M., \& Grossi, T. (2006). Disclosure of a Psychiatric Disability in Supported Employment: An Exploratory Study. International Journal of Psychosocial Rehabilitation, 11(1), 69-84.

Bates, D., Maechler, M., Bolker, B., \& Walker, S. (2014). lme4: Linear mixed-effects models using Eigen and S4. R package version 1.1-6. Retrieved from http://CRAN.R-project.org/package=lme4

Bricout, J. C., \& Bentley, K. J. (2000). Disability status and perceptions of employability by employers. Social Work Research, 24(2), 87-95.

Brohan, E., Henderson, C., Little, K., \& Thornicroft, G. (2010). Employees with mental health problems: Survey of UK employers' knowledge, attitudes and workplace practices. Epidemiologia e psichiatria sociale, 19(04), 326-332.

Bruyere, S. M., Erickson, W. A., \& VanLooy, S. (2004). Comparative Study of Workplace Policy and Practices Contributing to Disability Nondiscrimination. Rehabilitation psychology, 49(1), 28.

Butterworth, J., Whitney-Thomas, J., \& Shaw, D. (1997). The changing role of community based instruction: Strategies for facilitating workplace supports. Journal of Vocational Rehabilitation, 8(1), 9-20.

Carpenter, N. C., \& Paetzold, R. L. (2013). An examination of factors influencing responses to requests for disability accommodations. Rehabilitation psychology, 58(1), 18-27.

Colella, A. (2001). Coworker distributive fairness judgments of the workplace accommodation of employees with disabilities. Academy of Management Review, 26(1), 100-116.

Colella, A., Paetzold, R. L., \& Belliveau, M. A. (2004). Factors affecting coworkers' procedural justice inferences of the workplace accommodations of employees with disabilities. Personnel Psychology, 57(1), 1-23.

Corrigan, P. W., Kuwabara, S., Tsang, H., Shi, K., Larson, J., Lam, C. S., \& Jin, S. (2008). Disability and workrelated attitudes in employers from Beijing, Chicago, and Hong Kong. International Journal of Rehabilitation Research, 31(4), 347-350.

Dalgin, R. S., \& Bellini, J. (2008). Invisible disability disclosure in an employment interview: Impact on employers' hiring decisions and views of employability. Rehabilitation Counseling Bulletin, 52, 6-15.

Diksa, E., \& Rogers, E. S. (1996). Employer concerns about hiring persons with psychiatric disability: Results of the Employer Attitude Questionnaire. Rehabilitation Counseling Bulletin, 40, 31-44.

Dong, S., Oire, S. N., MacDonald-Wilson, K. L., \& Fabian, E. S. (2013). A comparison of perceptions of factors in the job accommodation process among employees with disabilities, employers, and service providers. Rehabilitation Counseling Bulletin, 56, 182-189.

Ellison, M. L., Russinova, Z., MacDonald-Wilson, K. L., \& Lyass, A. (2003). Patterns and correlates of workplace disclosure among professionals and managers with psychiatric conditions. Journal of Vocational Rehabilitation, 18(1), 3-13.

Fishbein, M., \& Ajzen, I. (1975). Belief, attitude, intention and behavior: An introduction to theory and research. Reading, MA: Addison-Wesley.

Florey, A. T., \& Harrison, D. A. (2000). Responses to informal accommodation requests from employees with disabilites: Multistudy evidence on willingness to comply. Academy of Management Journal, 43(2), 224-233.

Gates, L. B. (2000). Workplace accommodation as a social process. Journal of occupational rehabilitation, 10(1), 85-98.

Gething, L., \& Wheeler, B. (1992). The Interaction with Disabled Persons Scale: A new Australian instrument to measure attitudes towards people with disabilities. Australian Journal of Psychology, 44(2), 75-82.

Gilbride, D., Stensrud, R., Vandergoot, D., \& Golden, K. (2003). Identification of the characteristics of work environments and employers open to hiring and accommodating people with disabilities. Rehabilitation Counseling Bulletin, 46(3), 130-137.

Gouvier, W. D., Sytsma-Jordan, S., \& Mayville, S. (2003). Patterns of discrimination in hiring job applicants with disabilities: The role of disability type, job complexity, and public contact. Rehabilitation psychology, $48(3), 175-181$.

Hand, C., \& Tryssenaar, J. (2006). Small business employers' views on hiring individuals with mental illness. Psychiatric Rehabilitation Journal, 29(3), 166-173.

Hazer, J. T., \& Bedell, K. V. (2000). Effects of seeking accommodation and disability on preemployment evaluations. Journal of Applied Social Psychology, 30(6), 1201-1223.

Iacono, T., Tracy, J., Keating, J., \& Brown, T. (2009). The Interaction with Disabled Persons scale: Revisiting its internal consistency and factor structure, and examining item-level properties. Research in developmental disabilities, 30(6), 1490-1501. 
Irvine, A. (2011). Something to declare? The disclosure of common mental health problems at work. Disability and Society, 26(2), 179-192.

Jackson, C. J., Furnham, A., \& Willen, K. (2000). Employer willingness to comply with the disability discrimination act regarding staff selection in the UK. Journal of Occupational and Organizational Psychology, 73(1), 119-129.

Jans, L. H., Kaye, H. S., \& Jones, E. C. (2012). Getting hired: successfully employed people with disabilities offer advice on disclosure, interviewing, and job search. Journal of occupational rehabilitation, 22(2), 155165.

Koser, D. A., Matsuyama, M., \& Kopelman, R. E. (1999). Comparison of a physical and a mental disability in employee selection: an experimental examination of direct and moderated effects. North American Journal of Psychology, 1, 213-222.

Lee, B. A. (1997). Legal requirements and employer responses to accommodating employees with disabilities. Human Resource Management Review, 6(4), 231-251.

Loy, B. (2016). Workplace accommodations: Low cost, high impact. Retrieved from https://askjan.org/media/lowcosthighimpact.html

Markel, K. S., \& Barclay, L. A. (2009). Addressing the underemployment of persons with disabilities: Recommendations for expanding organizational social responsibility. Employee Responsibilities and Rights Journal, 21(4), 305-318.

Miller, B. K., \& Werner, S. (2005). Factors influencing the inflation of task performance ratings for workers with disabilities and contextual performance ratings for their coworkers. Human Performance, 18(3), 309329.

Popovich, P. M., Scherbaum, C. A., Scherbaum, K. L., \& Polinko, N. (2003). The assessment of attitudes toward individuals with disabilities in the workplace. The Journal of Psychology, 137(2), 163-177.

Riddell, S., Edward, S., Weedon, E., \& Ahlgren, L. (2010). Disability, skills and employment: a review of recent statistics and literature on policy and initiatives (Research report 59): Equality and Human Rights Commission (EHRC).

Schartz, H. A., Hendricks, D., \& Blanck, P. (2006). Workplace accommodations: Evidence based outcomes. Work: A Journal of Prevention, Assessment and Rehabilitation, 27(4), 345-354.

Scheid, T. L. (1999). Employment of individuals with mental disabilities: Business response to the ADA's challenge. Behavioral Sciences and the Law, 17(1), 73-91.

Scherbaum, C. A., Scherbaum, K. L., \& Popovich, P. M. (2005). Predicting job - related expectancies and affective reactions to employees with disabilities from Previous work experience. Journal of Applied Social Psychology, 35(5), 889-904.

Schur, L., Kruse, D., \& Blanck, P. (2005). Corporate culture and the employment of persons with disabilities. Behavioral sciences \& the law, 23(1), 3-20.

Schur, L., Nishii, L., Adya, M., Kruse, D., Bruyère, S. M., \& Blanck, P. (2014). Accommodating employees with and without disabilities. Human Resource Management, 53(4), 593-621.

Stone, D. L., \& Colella, A. (1996). A model of factors affecting the treatment of disabled individuals in organizations. Academy of Management Review, 21(2), 352-401. 


\section{Online APPENDIX}

\subsection{Additional Results Tables}

Table A1

Descriptive Statistics and Intercorrelations for Demographics and Scales

\begin{tabular}{lrrrrrrr} 
Variable & 1 & 2 & 3 & 4 & 5 & 6 & 7 \\
\hline 1. Female & --- & & & & & & \\
2. Age & $\mathbf{- . 2 6}$ & --- & & & & & \\
3. Psych disability contact & .14 & .01 & --- & & & & \\
4. Experience accommodation & -.05 &. $\mathbf{2 2}$ & $\mathbf{. 3 4}$ & --- & & & \\
5. Knowledge of legislation & -.06 & -.15 & .12 & .00 & --- & & \\
6. Productivity perceptions & .03 & -.01 & .17 & .09 &. $\mathbf{2 6}$ & --- & \\
7. Helpfulness & .12 & -.11 & .11 & .08 &. $\mathbf{2 1}$ & $\mathbf{. 5 5}$ & --- \\
8. Discomfort & .02 & -.10 & -.34 & -.32 & -.09 & $\mathbf{- . 3 4}$ & $\mathbf{- . 3 1}$ \\
\hline Note. $\mathrm{n}=159$. Female is coded $0=$ male, $1=$ female. Absolute correlations greater \\
than or equal to .15 are significant $(p<.05)$ are bolded.
\end{tabular}




\section{Table A2}

Multilevel Model Predicting Vignette Ratings from Manipulated Factors

\begin{tabular}{lcccc}
\hline Predictor & Empathy & Legitimacy & Necessity & Rated Cost \\
\hline Intercept & $4.16^{*}(0.04)$ & $4.39^{*}(0.03)$ & $3.81^{*}(0.04)$ & $3.07^{*}(0.05)$ \\
Employer Characteristics & & & & \\
$\quad$ Female & $0.06(0.04)$ & $0.08^{*}(0.04)$ & $0.08^{*}(0.04)$ & $0.11^{*}(0.05)$ \\
Age & $0.04(0.04)$ & $0.03(0.04)$ & $0.03(0.04)$ & $0.09(0.05)$ \\
Psych disability contact & $0.07(0.05)$ & $0.06(0.04)$ & $0.06(0.04)$ & $-0.06(0.05)$ \\
Experience with accommodation & $0.03(0.05)$ & $-0.01(0.04)$ & $-0.01(0.04)$ & $0.01(0.05)$ \\
Knowledge of legislation & $0.00(0.04)$ & $0.01(0.04)$ & $0.01(0.04)$ & $-0.07(0.05)$ \\
Attitude: productivity perceptions & $0.07(0.05)$ & $0.10^{*}(0.04)$ & $0.10^{*}(0.04)$ & $-0.15^{*}(0.06)$ \\
Attitude: Helpfulness & $0.12^{*}(0.05)$ & $0.09^{*}(0.04)$ & $0.09^{*}(0.04)$ & $-0.06(0.06)$ \\
Attitude: Discomfort & $0.07(0.05)$ & $0.04(0.04)$ & $0.04(0.04)$ & $-0.03(0.06)$ \\
Vignette Factors & & & & \\
Manipulated Cost & $-0.05^{*}(0.02)$ & $-0.03^{*}(0.02)$ & $-0.36^{*}(0.04)$ & $1.18^{*}(0.05)$ \\
Severity & $0.04^{*}(0.02)$ & $0.08^{*}(0.02)$ & $-0.03^{*}(0.03)$ & $0.27^{*}(0.04)$ \\
Type: Psychological & $-0.15^{*}(0.02)$ & $-0.13^{*}(0.02)$ & $-0.43^{*}(0.03)$ & $-0.35^{*}(0.04)$ \\
& & & & \\
SD Intercept & 0.51 & 0.41 & 0.46 & 0.54 \\
SD Residual & 0.40 & 0.36 & 0.71 & 0.87 \\
Deviance & 2459.1 & 1981.2 & 4429.3 & 5193.0 \\
\hline
\end{tabular}

Note. Numbers represent estimates of fixed effects with standard errors in brackets.

All dependent variables are on a 1 to 5 scale. All employer characteristics were $\mathrm{z}$ score standardized.

${ }^{*} p<.05$ 

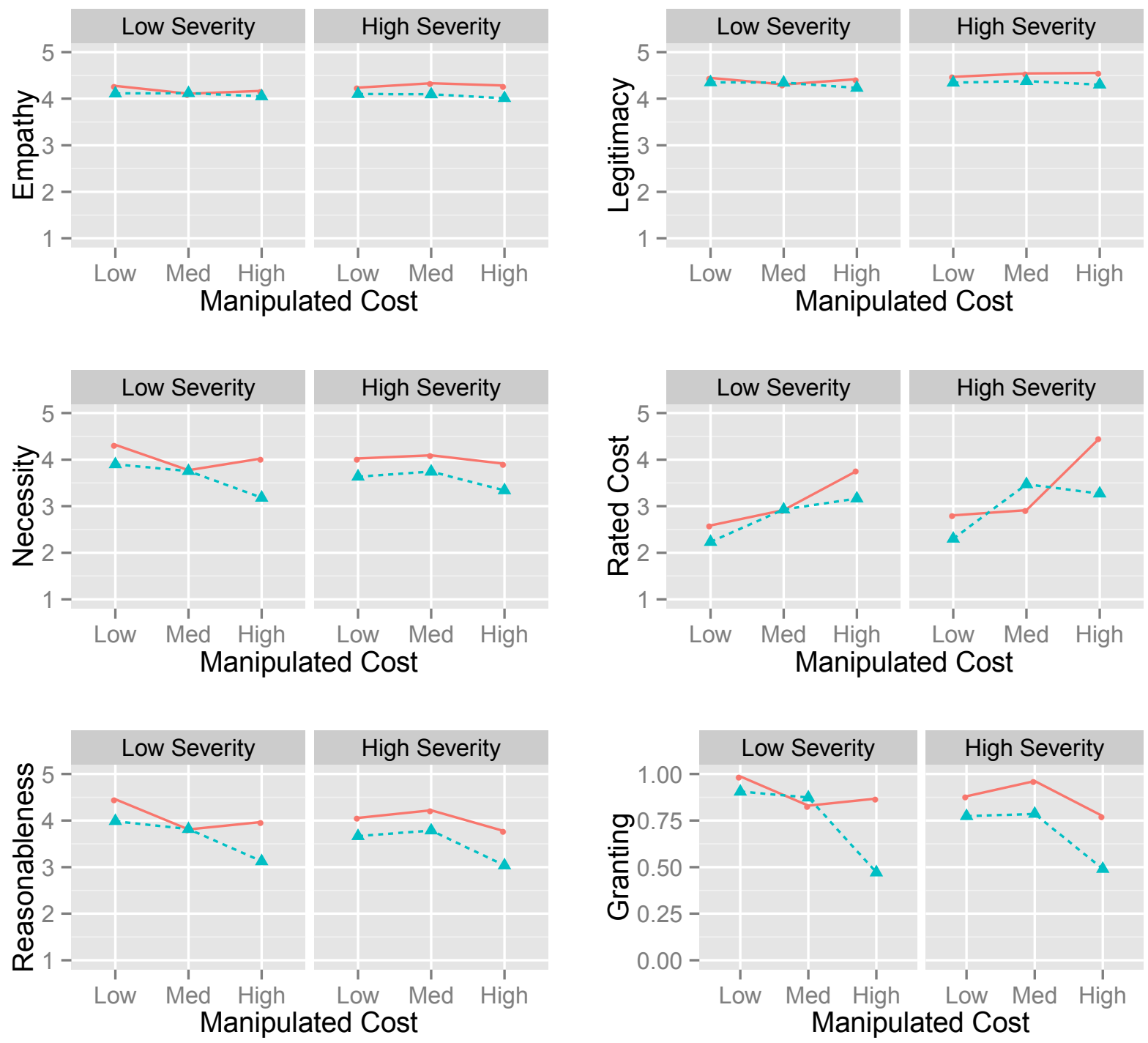

Physical --A-- Psychological

Figure A1. Mean vignette responses by manipulated vignette factors. 


\subsection{Vignettes}

Please note that the following key has been used to classify each vignette (these classification codes were not presented to participants):

\begin{tabular}{|c|c|c|c|c|}
\hline & Text & $\begin{array}{l}\text { Seve } \\
\text { rity }\end{array}$ & Cost & Type \\
\hline 1 & $\begin{array}{l}\text { You have an executive assistant, whose responsibilities } \\
\text { include scheduling of meetings and appointments, preparing } \\
\text { reports and presentations and overseeing office operations. } \\
\text { He/she has recently been diagnosed with a mild visual } \\
\text { impairment, which will impact all aspects of their role. } \\
\text { He/she has requested a larger desktop monitor in their } \\
\text { office. }\end{array}$ & low & low & physical \\
\hline 2 & $\begin{array}{l}\text { You have an executive assistant, whose responsibilities } \\
\text { include scheduling of meetings and appointments, preparing } \\
\text { reports and presentations and overseeing office operations. } \\
\text { He/she has recently been diagnosed with a mild visual } \\
\text { impairment, which will impact all aspects of their role. } \\
\text { He/she has requested access to frequent eye-rest breaks } \\
\text { away from his/her computer screen, and job sharing to } \\
\text { decrease his/her time preparing reports and presentations. }\end{array}$ & low & $\begin{array}{l}\text { mod } \\
\text { erate }\end{array}$ & physical \\
\hline 3 & $\begin{array}{l}\text { You have an executive assistant, whose responsibilities } \\
\text { include scheduling of meetings and appointments, preparing } \\
\text { reports and presentations and overseeing office operations. } \\
\text { He/she has recently been diagnosed with a mild visual } \\
\text { impairment, which will impact all aspects of their role. } \\
\text { He/she has requested the implementation of adaptive } \\
\text { technology in his/her office, including enhanced screen } \\
\text { display, and speech and Braille output, and also time off for } \\
\text { adaptive technology training. }\end{array}$ & low & high & physical \\
\hline 4 & $\begin{array}{l}\text { You have an administrative assistant who helps with day-to- } \\
\text { day business, including workforce co-ordination, data } \\
\text { management, research and client liaison. He/she has } \\
\text { recently been diagnosed with bipolar disorder, and } \\
\text { experiences mild difficulties with concentration and their } \\
\text { short-term memory. He/she has requested a dual noise- } \\
\text { cancelling headset to listen to music when not talking on the } \\
\text { telephone, to minimise distractions and enhance } \\
\text { concentration. }\end{array}$ & low & low & $\begin{array}{l}\text { psychologi } \\
\text { cal }\end{array}$ \\
\hline 5 & $\begin{array}{l}\text { You have an administrative assistant who helps with day-to- } \\
\text { day business, including workforce co-ordination, data } \\
\text { management, research and client liaison. He/she has } \\
\text { recently been diagnosed with bipolar disorder, and } \\
\text { experiences mild bursts of increased energy, reduced } \\
\text { judgement and attendance issues. He/she has requested } \\
\text { flexible work hours and job sharing or a temporary job }\end{array}$ & low & $\begin{array}{l}\text { mod } \\
\text { erate }\end{array}$ & $\begin{array}{l}\text { psychologi } \\
\text { cal }\end{array}$ \\
\hline
\end{tabular}




\begin{tabular}{|c|c|c|c|c|}
\hline & restructure to assist with symptom management. & & & \\
\hline 6 & $\begin{array}{l}\text { You have an administrative assistant who helps with day-to- } \\
\text { day business, including workforce co-ordination, data } \\
\text { management, research and client liaison. He/she has } \\
\text { recently been diagnosed with bipolar disorder, and } \\
\text { experiences mild insomnia, occasional fatigue, and reduced } \\
\text { energy. He/she has requested that they be set up with a } \\
\text { home office to be able to work from home. He/she has also } \\
\text { requested a self-paced workload to assist with symptom } \\
\text { management. }\end{array}$ & low & high & $\begin{array}{l}\text { psychologi } \\
\text { cal }\end{array}$ \\
\hline 7 & $\begin{array}{l}\text { One of your consultants, whose responsibilities include data } \\
\text { collection and analysis, preparing business reports and } \\
\text { proposals, and client liaison, has recently returned to work } \\
\text { from a spinal cord injury. As wheelchair access to and } \\
\text { within the office is not feasible, he/she has requested to be } \\
\text { set up with access to your organisation's internal server and } \\
\text { network on his/her home office, which already } \\
\text { accommodates his/her wheelchair. }\end{array}$ & high & low & physical \\
\hline 8 & $\begin{array}{l}\text { One of your consultants, whose responsibilities include data } \\
\text { collection and analysis, preparing business reports and } \\
\text { proposals, and client liaison, has recently returned to work } \\
\text { from a spinal cord injury. Due to being limited to a } \\
\text { wheelchair, he/she has requested flexible working hours, } \\
\text { more frequent breaks and job sharing to assist in } \\
\text { transitioning back to work, given that wheelchair access to } \\
\text { and within the office already exists. }\end{array}$ & high & $\begin{array}{l}\text { mod } \\
\text { erate }\end{array}$ & physical \\
\hline 9 & $\begin{array}{l}\text { One of your consultants, whose responsibilities include data } \\
\text { collection and analysis, preparing business reports and } \\
\text { proposals, and client liaison, has recently returned to work } \\
\text { from a spinal cord injury. Due to being limited to a } \\
\text { wheelchair, he/she has requested a re-model to his/her } \\
\text { workstation, access to a disabled restroom, as one does not } \\
\text { currently exist, department-wide disability sensitivity } \\
\text { training, and a full ergonomic assessment. }\end{array}$ & high & high & physical \\
\hline 10 & $\begin{array}{l}\text { A project manager, whose key responsibilities encompass } \\
\text { the management of a key business project, has recently been } \\
\text { diagnosed with schizophrenia. He/she experiences severe } \\
\text { drowsiness as a result of their medication, which impacts on } \\
\text { their ability to concentrate at work and subsequently their } \\
\text { deteriorating work performance. He/she has requested to be } \\
\text { moved from an open plan office to a private office, which is } \\
\text { presently vacant, to assist with symptom management and } \\
\text { enhance work performance. }\end{array}$ & high & low & $\begin{array}{l}\text { psychologi } \\
\text { cal }\end{array}$ \\
\hline 11 & $\begin{array}{l}\text { A project manager, whose key responsibilities encompass } \\
\text { the management of a key business project, has recently been } \\
\text { diagnosed with schizophrenia. He/she experiences tremors }\end{array}$ & high & $\begin{array}{l}\text { mod } \\
\text { erate }\end{array}$ & $\begin{array}{l}\text { psychologi } \\
\text { cal }\end{array}$ \\
\hline
\end{tabular}




\begin{tabular}{|l|l|l|l|l|}
\hline & $\begin{array}{l}\text { and restlessness as a side effect of their medication, which } \\
\text { impact on their work motivation and interest and he/she } \\
\text { subsequently experiences attendance issues. He/she has } \\
\text { requested flexible work scheduling, more frequent rest } \\
\text { breaks, and fortnightly sessions with a psychiatrist to assist } \\
\text { with symptom management and transitioning back to work. }\end{array}$ & & & \\
\hline 12 & $\begin{array}{l}\text { A project manager, whose key responsibilities encompass } \\
\text { the management of a key business project, has recently been } \\
\text { diagnosed with schizophrenia. He/she experiences blurred } \\
\text { vision as a medication side effect, which results in him/her } \\
\text { appearing emotionally detached and socially withdrawn at } \\
\text { work. He/she has requested that mandatory sensitivity } \\
\text { training be provided to his/her colleagues, and that all future } \\
\text { communication be directed to his/her deputy, who will have } \\
\text { the power to authorise and delegate work, until a job re- } \\
\text { structure be undertaken and put in place. }\end{array}$ & $\begin{array}{l}\text { psychologi } \\
\text { cal }\end{array}$ \\
\hline
\end{tabular}

The six items that were presented with each vignette are below:

1) This employee is someone with whom I can empathise.

(1) Strongly disagree, (2) Disagree, (3) Neither disagree nor agree, (4) Agree, (5) Strongly Agree

2) Irrespective of the accommodation, I believe this specific disability to be a legitimate disability.

(1) Strongly disagree, (2) Disagree, (3) Neither disagree nor agree, (4) Agree, (5) Strongly Agree

3) This specific accommodation is necessary for organisational productivity.

(1) Strongly disagree, (2) Disagree, (3) Neither disagree nor agree, (4) Agree, (5) Strongly Agree

4) What cost would you associate with this specific work accommodation?

(1) Very inexpensive, (2) Moderately inexpensive, (3) Neither inexpensive nor expensive,

(4) Moderately expensive, (5) Very expensive

$5)$ This work accommodation request is reasonable.

(1) Strongly disagree, (2) Disagree, (3) Neither disagree nor agree, (4) Agree, (5) Strongly Agree

6) Would you grant this specific work accommodation request?

(0) No, (1) Yes 


\subsection{Knowledge of Disability Legislation survey - Australian Adaptation}

Note: This measure was adapted to the Australian context from Hazer and Bedell (2000).

This is an exercise designed to measure your knowledge about the Australian Disability Discrimination Act (DDA) of 1992. Whilst you may not be familiar with this legislation, your responses are very important. Some of the following statements reflect the content of the DDA. Please indicate whether you believe that each statement is True or False by selecting ' $\mathrm{T}$ ' or ' $\mathrm{F}$ '.

\begin{tabular}{|c|c|c|}
\hline $\begin{array}{l}\text { Numbe } \\
\mathrm{r}\end{array}$ & Statement & $\begin{array}{l}\text { Response } \\
(\text { correct }=\dagger)\end{array}$ \\
\hline 1 & $\begin{array}{l}\text { It is unlawful to collect information from a person with a disability for } \\
\text { the purpose of discriminating against that person }\end{array}$ & $\dagger \mathrm{T} \mid \mathrm{F}$ \\
\hline 2 & $\begin{array}{l}\text { An employer cannot make any inquiries of an employee about their } \\
\text { ability to do the inherent requirements of the job, identify reasonable } \\
\text { adjustments etc. }\end{array}$ & $\mathrm{T} \mid \mathrm{F} \dagger$ \\
\hline 3 & $\begin{array}{l}\text { Employers may screen out job applicants with disabilities by giving } \\
\text { them tests that are not related to the job }\end{array}$ & $\mathrm{T} \mid \mathrm{F} \dagger$ \\
\hline 4 & $\begin{array}{l}\text { Employers may deny a job to a qualified individual with a disability } \\
\text { based on the fact that the individual will require reasonable } \\
\text { accommodation on the job }\end{array}$ & $\mathrm{T} \mid \mathrm{F} \dagger$ \\
\hline 5 & $\begin{array}{l}\text { Assuming no undue hardship to the organisation, employers are required } \\
\text { to ensure that any employment-related tests are fairly administered to } \\
\text { applicants who have disabilities that may affect test-taking (e.g., } \\
\text { blindness, deafness, speaking difficulties) }\end{array}$ & $\dagger \mathrm{T} \mid \mathrm{F}$ \\
\hline 6 & $\begin{array}{l}\text { An employer can seek advice from an employee about the reasonable } \\
\text { adjustments they may need }\end{array}$ & $\dagger \mathrm{T} \mid \mathrm{F}$ \\
\hline 7 & $\begin{array}{l}\text { Assuming no undue hardship to the organisation, employers are required } \\
\text { to modify equipment (e.g., telephones, computers, desks) for otherwise } \\
\text { qualified persons with disabilities who request modifications }\end{array}$ & $\dagger \mathrm{T} \mid \mathrm{F}$ \\
\hline 8 & $\begin{array}{l}\text { Assuming no undue hardship to the organisation, employers are required } \\
\text { to modify work schedules (e.g., breaks, part-time employment) for } \\
\text { qualified persons with disabilities who request such modifications }\end{array}$ & $\dagger \mathrm{T} \mid \mathrm{F}$ \\
\hline 9 & $\begin{array}{l}\text { An employer may choose not to hire a qualified applicant who has a } \\
\text { psychiatric disability (i.e., mental illness) if the employer is } \\
\text { uncomfortable with this type of disability }\end{array}$ & $\mathrm{T} \mid \mathrm{F} \dagger$ \\
\hline 10 & $\begin{array}{l}\text { Employers are required to restructure jobs (e.g., reassign job duties, } \\
\text { change working environment) for persons with disabilities who are } \\
\text { otherwise qualified, assuming there is not undue hardship to the } \\
\text { organisation }\end{array}$ & $\dagger \mathrm{T} \mid \mathrm{F}$ \\
\hline 11 & $\begin{array}{l}\text { Employers can speak with an existing employee's or potential } \\
\text { employee's previous employers, to gain information about how a } \\
\text { disability affected their work performance and to make employment } \\
\text { decisions }\end{array}$ & $\mathrm{T} \mid \mathrm{F} \dagger$ \\
\hline
\end{tabular}




\begin{tabular}{|l|l|c|}
\hline 12 & $\begin{array}{l}\text { Employers are required to make existing facilities used by employees } \\
\text { accessible to persons with disabilities, assuming there is no undue } \\
\text { hardship to the organisation }\end{array}$ & $\uparrow \mathrm{T} \mid \mathrm{F}$ \\
\hline 13 & $\begin{array}{l}\text { Employers may require that their employees take medical examinations } \\
\text { that are not related to their jobs in order to determine if any of their } \\
\text { employees has a disability }\end{array}$ & $\mathrm{T} \mid \mathrm{F} \uparrow$ \\
\hline 14 & $\begin{array}{l}\text { Employers may ask job applicants if they have the ability to perform } \\
\text { essential job-related functions }\end{array}$ & $\uparrow \mathrm{T} \mid \mathrm{F}$ \\
\hline
\end{tabular}

\subsection{Productivity Perceptions of Disabled Workers and Helpfulness towards} Disabled Workers

Source: Scherbaum, Scherbaum \& Popovich (2005)

\begin{tabular}{|c|c|c|}
\hline & Item Text & $\begin{array}{l}\text { Reversa } \\
1^{\mathrm{a}}\end{array}$ \\
\hline & Productivity Perceptions of Disabled Workers & \\
\hline 1 & Employees with disabilities can hold supervisory positions & 1 \\
\hline 2 & $\begin{array}{l}\text { Employees with disabilities increase the workload of their } \\
\text { co-workers }\end{array}$ & -1 \\
\hline 3 & $\begin{array}{l}\text { Employees with disabilities can improve the atmosphere of } \\
\text { the workplace }\end{array}$ & 1 \\
\hline 4 & $\begin{array}{l}\text { Employees with disabilities need constant help to perform } \\
\text { common work tasks }\end{array}$ & -1 \\
\hline 5 & Employees with disabilities can work on hazardous jobs & 1 \\
\hline 6 & $\begin{array}{l}\text { Employees with disabilities require more supervision than } \\
\text { non-disabled employees }\end{array}$ & -1 \\
\hline 7 & $\begin{array}{l}\text { Employees with disabilities slow down the rate at which } \\
\text { work is completed }\end{array}$ & -1 \\
\hline & Helpfulness towards Disabled Workers & \\
\hline 8 & $\begin{array}{l}\text { I would socialise with a co-worker who was disabled } \\
\text { during my work breaks }\end{array}$ & 1 \\
\hline 9 & $\begin{array}{l}\text { I would share my workspace or desk with a co-worker } \\
\text { who was disabled }\end{array}$ & 1 \\
\hline 10 & $\begin{array}{l}\text { I would assist a new co-worker who was disabled in } \\
\text { learning his or her new job }\end{array}$ & 1 \\
\hline 11 & $\begin{array}{l}\text { I would take on more work to assist a co-worker who was } \\
\text { disabled }\end{array}$ & 1 \\
\hline 12 & $\begin{array}{l}\text { I would avoid working in a group with a co-worker who } \\
\text { was disabled }\end{array}$ & -1 \\
\hline 13 & $\begin{array}{l}\text { I would accept a job that would require me to work closely } \\
\text { with co-workers who are disabled }\end{array}$ & 1 \\
\hline 14 & $\begin{array}{l}\text { I would change the way I do my job to make it easier for a } \\
\text { co-worker who was disabled to do their job }\end{array}$ & 1 \\
\hline
\end{tabular}

${ }^{\mathrm{a}} 1$ = not reversed; $-1=$ reversed 